\title{
GREGÓRIO DE MATOS NO RITMO DAS ANÁFORAS
}

PEDRo MARQUES

\section{RESUMO}

A anáfora é um arranjo de palavras ou expressões que iniciam versos, consecutivos ou alternados. Como figura retórica, ela reforça a voz do orador, pois a recorrência entoativa indica os termos chaves para o convencimento do ouvinte. Na composição poética, se as rimas regularizam a sonoridade ao final, a anáfora cria certa uniformidade acústica na nascente dos versos, num interessante efeito de contra rima. A aplicação culta dessa figura - que alcança graça poética, convencimento retórico e didática teológica - será analisada em dois sonetos sacros atribuídos a Gregório de Matos e Guerra (1633-1696).

Palavras-Chave: Poética do século XVII; Gregório de Matos; ritmo poético.

I.

A anáfora é um arranjo significativo de palavras reincidentes, com ou sem variação morfossintática, em início de enunciados consecutivos ou alternados. Um radical pode ressurgir como verbo, substantivo ou adjetivo (quedei, queda ou quedo). Uma frase pode se replicar de modo não idêntico (e quedei ferido, e ferido na queda ou e quedo e ferido). No grego antigo anaphorá, o prefixo aná assinala repetição, enquanto phorá o verbo phoréo, com sentido de levar, transportar. ${ }^{2}$ É essa transferência de material linguístico, sobre um padrão rítmico-entoacional, que o poeta costuma estilizar. Na poesia do século XVII, a aplicação retórica da anáfora contribui

\footnotetext{
* Professor de Literatura Brasileira na Escola de Filosofia, Letras e Ciências Humanas da Universidade Federal de São Paulo/ UNIFESP, Guarulhos, São Paulo, Brasil.

E-mail: pedro_marques77@hotmail.com

2 Cf. FIORIN, 2014, p. 118-119.
} 
para a harmonização dos dados semânticos, sonoros e persuasivos, tanto mais tensionados pelo uso agudo, simultâneo e diversificado dos topos e figuras. Daqueles esquemas que, segundo Quintiliano (35 d.C. - 100 d.C.), "atraem para o orador a atenção dos ouvintes e não permitem que se perca a força” (2016, p. 485), a anáfora uniformiza, ainda, as curvas entoacionais do homem discreto, do murmúrio íntimo à récita coletiva, sustentando a impostação decorosa, algo entre a extensão do tenor e a do barítono.

A poesia oratória do período busca a elocução culta que não deve se confundir com a pronúncia vulgar. Composta sob as artes da linguagem (o trivium gramática, dialética e retórica), é compartilhada por um reduzido número de letrados, muito embora acessada de oitiva ao menos pela geral urbana. Escrito para ser lido, dito e escutado, grande parte do corpus Gregório de Matos (1633-1696) nobilita aquilo que Luiz Carlos Cagliari (2012, p. 35) chama de "processo de empatia fonética", que é quando, na fala corrente, "o ouvinte reproduz os mecanismos articulatórios produzidos pelo falante e, desse modo, pode sentir o que ouve, como se ele os pronunciasse". Num mundo em que a poesia, como item da vida civil, decanta a norma metropolitana, uma glosa em décimas ou um soneto encomiástico pactua o enunciado distintivo, a "comunicação fonética específica, padronizada no corpo e na mente” (p. 35.), no caso, o auditório cortês, físico ou virtual, da Bahia seiscentista. Assim, dispor e compreender, num poema, figuras de linguagem estilizadas, produz e confirma, no partícipe de ambientes estabelecidos como civilizados, uma sociabilidade de expressão necessariamente aristocrática.

II.

Na lírica sacra atribuída a Gregório de Matos, há prodigiosas teias de anáforas. Em tais ocorrências, enquanto a grade rítmica regulariza a sonoridade esperada ao final do verso, a anáfora cria um tecido acústico na elocução nascente em cada estrofe ou verso. $\mathrm{O}$ resultado é como se fosse um movimento pendular entre rimas pouco previsíveis no plano da frequência e da posição, e rimas muito previsíveis no plano estrutural 
de formas como o soneto. Assim, a aplicação dessa figura em "Buscando a Cristo” está francamente voltada para a produção da graça poética, do convencimento retórico e da didática teológica. A pilastra armada pela recorrência de $a$ vós, à esquerda, opera como monodia (timbre invariável), enquanto o sistema de rimas, à direita, faz as vezes de melodia (timbres variados em -ados, -ertos, -ar-me e -ir-me), tudo no compasso do verso heroico. Tal jogo contrapontístico que fala e se mostra no corpo do texto entre uma nota de um lado e quatro notas de outro - encontra, em termos discursivos, a dialética entre a imutabilidade da misericórdia de Cristo, a quem sempre se busca sob qualquer circunstância; e a mutabilidade das agruras do homem, multiplicadas a partir do pecado original, estopim da perdição humana.

\section{Buscando a CRisto}

A vós correndo vou, braços sagrados, nessa Cruz sacrossanta descobertos que, para receber-me, estais abertos, e, por não castigar-me, estais cravados.

A vós, divinos olhos, eclipsados de tanto sangue e lágrimas cobertos, pois, para perdoar-me, estais despertos, e, por não condenar-me, estais fechados.

A vós, pregados pés, por não deixar-me, a vós, sangue vertido, para ungir-me, a vós, cabeça baixa, por chamar-me.

A vós, lado patente, quero unir-me, a vós, cravos preciosos, quero atar-me, para ficar unido, atado e firme.

(MATOS, 1967, p. 32)

A relevância do seguimento $a$ vós cresce em andamento adagietto, conveniente à prece. Primeiro, encabeça os quartetos, como fosse a 
própria cabeça pendente de Cristo na cruz, depois inicia quase todos os versos dos tercetos. A repetição encorpa a voz poético-litúrgica, ornamenta a tessitura suplicante, delibera, na declamação, o efeito de equívoco entre a vós/a voz, justamente num sintagma vocativo. Quanto mais a grandeza caridosa de Jesus amplifica-se, mais fica o eu humílimo, num gesto de afirmação do status quo católico. Espécie de sermão em miniatura, há moderação e familiaridade, como ensina Antônio Vieira (1608-1697), no seu Sexagésima (1655), ao pregador: "falar mais ao ouvido que aos ouvidos, não só concilia maior atenção, mas naturalmente e sem força se insinua, entra, penetra e se mete na alma" (VIEIRA, [1655] 2006, p. 46). A dramatização da sujeição do homem temente ao Salvador fagulha agudezas, dispostas em sintaxes paralelas. No terceiro verso, o eu discursivo interpreta os braços abertos de Jesus como acolhimento, como abraço da salvação, para "receber-me, estais abertos"; no quarto, lê nas mãos pregadas a misericórdia de Jesus, cujo juízo corre a perdoar mas freia ao castigar, "e, por não castigar-me, estais cravados". No sétimo verso, dispõem-se os olhos divinos de Cristo alertas e perfeitos no salvar, para "perdoa-me, estais despertos"; já no oitavo, os olhos humanos do Senhor vão distraídos e imperfeitos no punir, "para condenar-me, estais fechados".

A arquitetura do soneto, cujas vigas são ornadas com anáforas, está às ordens do pacto de sujeição católico, isto é, estiliza o povo reunido num único corpo (no caso, o império português), encabeçado pelo Rei, ratificado pelo Papa e, portanto, sob desígnios de Deus. O cristão aliena sua vontade individual, transferindo-a à figura místico-política do Rei. Liberdade, nesta perspectiva, significa servidão livre, subordinação à cabeça divino-real. O público (leitores e ouvintes) é a totalidade do corpo místico, diferente do mercado consumidor ou da opinião pública liberal, que se desenharia a partir do final do século XVIII, como anota João Adolfo Hansen em A civilização pela palavra (2007). ${ }^{1}$ Em Portugal, essa doutrina emanava da Universidade de Coimbra até os colégios da metrópole e das colônias por meio de documentos, métodos e práticas de pregação. Uma

Cf. p. 19-41. 
rede bastante efetiva em prol da normalização do pensar, crer e proceder. A partir do século XIX, a valoração da autonomia do homem condenaria a submissão do artista ao sistema colonial de poder. Transformado pela narrativa romântica em alguém dotado de psicologia própria, Gregório de Matos não passaria de um adulador ou libertino. Para Abdias Nascimento ([1978] 2018, p. 154), inclusive, ele estaria entre os afrodescendentes aculturados, "ansiosos pela aceitação e o reconhecimento da sociedade vigente, ambicionando atingir os níveis mais elevados da hierarquia social" branca e lusitana. Tomado assim como personalidade coesa, Gregório de Matos teria se submetido conscientemente a "um processo de branquificação interior” (p. 154), típico anti-exemplo para Abdias Nascimento (2018) que, na década de 1970, denunciava o racismo institucional do estado e resgatava a ancestralidade africana da população brasileira.

A ação educacional e catequética do século XVII harmoniza os homens entre si e em Deus como partes do todo místico-religioso que é o estado português, cuja soberania sacra naturaliza desigualdades sociorraciais e posições hierárquicas. Cada posto pessoal, social e estamental é representado por dados constitutivos, do que se diz ao que se veste, que o mantém e confirma como subordinado ao governo do Rei. O soneto, assim, atualiza a voz do homem discreto fiel à Fé, ao Rei e à Lei; corrobora a ordem das coisas na sua tripla ação retórica: convence pela salvação e obediência, educa sobre o mistério sacrificial e diverte com engenho e agudeza. Se a anáfora, no cristianismo, é uma das denominações da prece eucarística, isto é, da louvação ao sacrifício de Jesus com vistas a nos transportarmos a Deus, promove-se aqui, além de tudo, uma extraordinária agudeza capaz de alinhar três planos: a repetição poética, a reiteração retórica e a renovação religiosa.

O soneto, por fim, opera como écfrase, ou seja, como uma descrição ou versão poética da conhecida escultura, material ou imaginada, do Bom Jesus do Matosinhos ou Nosso Senhor de Bouças: Cristo com o estrabismo post mortem, um olho mirando o céu e outro entregue à terra, os pés pregados em separado na cruz. Tudo pulsa entre anáforas e rimas 
repercutindo como o sino da Páscoa, ora batendo um lamentando à morte, ora percutindo o anúncio da ressureição. Por isso, a configuração desse rosto de Cristo: um olho na Cidade de Deus, no fim dos tempos; outro na Cidade dos Homens, no tempo da carne vã. $\mathrm{O}$ sino poético de Gregório de Matos enquadra, em discurso poético, o mistério de Cristo no Monte Calvário, o "anfiteatro de suas penas", o "teatro de suas gloriosas exaltações”, como prega Frei João de Deus Monte Alverne (1737, p. 70), num sermão de 1733 dedicado a esse Jesus de Matosinhos, considerado uma das imagens mais típicas e arcaicas do catolicismo lusitano.

Alfredo Bosi (1977, p. 24) indaga sobre a possibilidade da "série temporal do discurso" reproduzir, ou não, "o imediato, o simultâneo, o 'finito' da imagem”. Ao que Paulo Martins (2016) responderia, para simular um diálogo entre os estudiosos, com a figura retórica da écfrase autônoma, a partir da qual "o enunciador ecfrástico de uma obra de arte", prescindindo da "natureza estática e espacial da pintura, do relevo, do mosaico ou da tapeçaria”, e buscando descrever o dado pictórico ou táctil no tempo fluente da língua, imprimiria "à imago o envolvimento emocional ou patético do descritor” (p. 170). O poema de Gregório de Matos, mesmo enquanto enunciado seriado, produziria, portanto, esse efeito de simultaneidade imagética e patética - do Cristo crucificado e do Estado Teológico e Político de Portugal sobre todos os viventes - ao delinear circuitos de recorrências rítmicas, sonoras, semânticas, sintáticas e, principalmente, anafóricas. Aqui, o leitor/ouvinte, ao transmudar-se em expectador, aceita seu lugar no teatro da fé.

As reproduções fotográficas a seguir, inseridas para ilustrar o jogo armado pelo poema gregoriano, pertencem ao trabalho As imagens do Senhor Bom Jesus, veneradas em Matosinhos (Portugal) e em Congonhas do Campo (Brasil), de Edgard de Cerqueira Falcão (1959). O estudo possui um acervo de imagens acompanhadas de interessantes comentários. Vale mencionar, ainda, que tal imagética reaparece e se transforma em outros poetas brasileiros, inclusive até o século XX. Recomendo, por exemplo, a leitura de pelo menos cinco sonetos religiosos e um tanto quanto anafóricos de José Albano (1882-1923): “Senhor, assim pregado ao duro 
lenho", "Ó todos que sabeis o que é tristeza", "Não quero mais viver sem sofrimento", "Eu não sabia que me amavas tanto" e "Bom Jesus, amador das almas puras” (1993, p. 60-64).

Figura 1- Senhor Bom Jesus, Matosinhos, Portugal

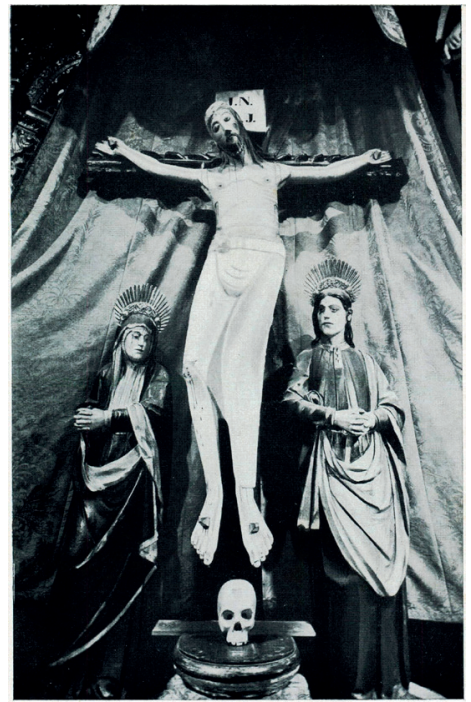

Fonte: (FALCÂO, 1959, p. 163-169).

Figura 2 -Detalhe Senhor Bom Jesus, Matosinhos, Portugal

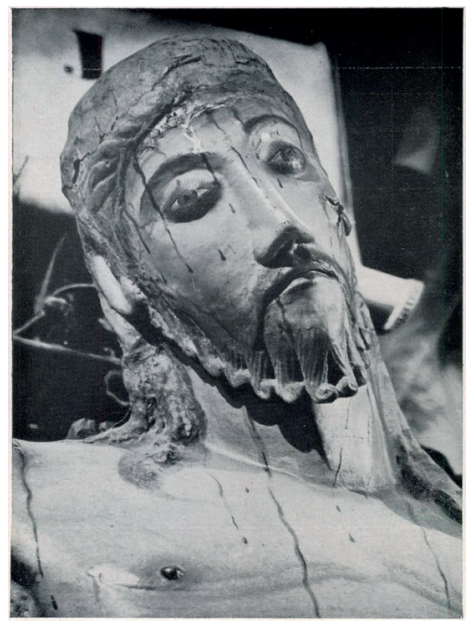

Fonte: (FALCÃO, 1959, p. 163-169). 
Figura 3 -Senhor Bom Jesus jacente, Congonhas do Campo, Minas Gerais, Brasil

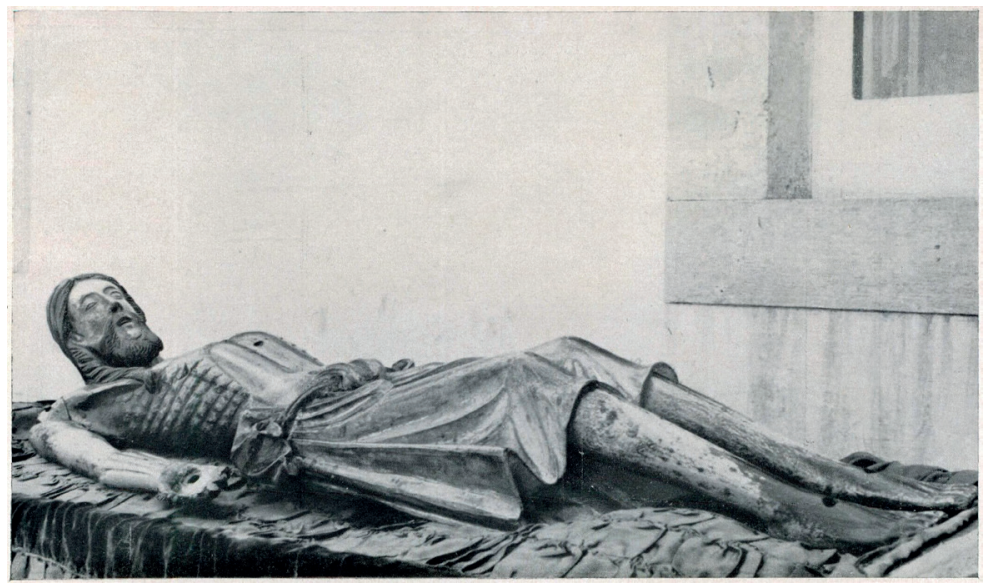

Fonte: (FALCÂO, 1959, p. 163-169).

Figura 4 - Detalhe Senhor Bom Jesus jacente, Congonhas do Campo, Minas Gerais, Brasil

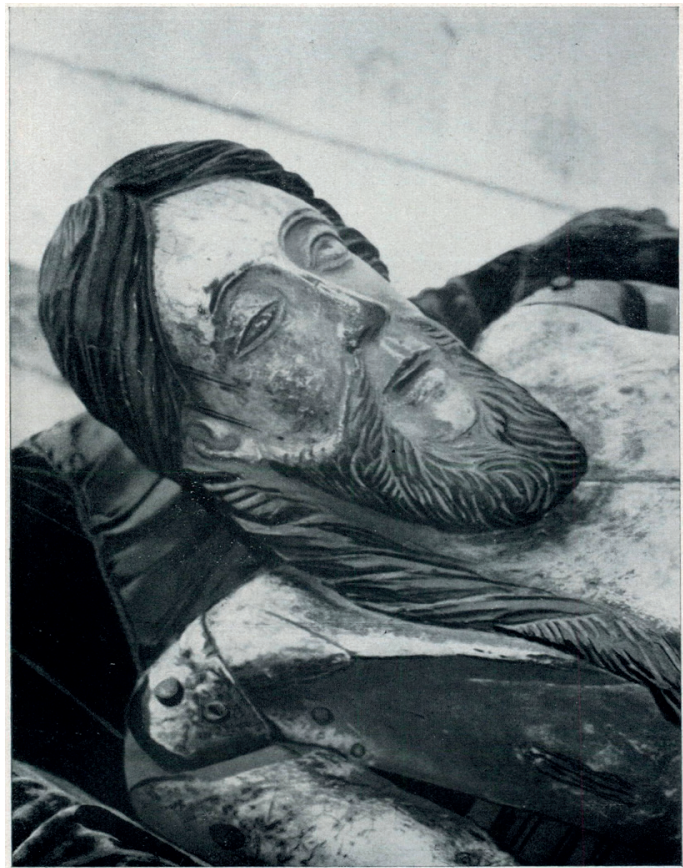

Fonte: (FALCÂO, 1959, p. 163-169). 
III.

O soneto a seguir, por sua vez, coloca em curso o que chamo rima anafórica, a qual transforma as duas ou três sílabas finais, da penúltima palavra do verso, numa última palavra autônoma. O sistema aumenta o volume do discurso musical em relação ao anterior, pois a duplicação sonora faz soar, ao mesmo tempo e em série, o sentido do sintagma matriz e o do seu acréscimo. Essa simultaneidade semântico-acústica produz acordes consonantes, quando afirma a salvação celeste (no Cristo afamado amado há verdade), e dissonantes, quando reconhece a danação terrena (na loucura do homem, há de haver cura). Rogério Chociay (1993) toma o recurso como rima dobrada ou rima ecoica, talvez sugestionado pelo mazdobre e o dobre medievais, que levavam o mesmo vocábulo a ecoar em diversos lugares da estrofe, feito um carrilhão assimétrico. Se no soneto anterior a estrutura anafórica criava duas colunas sonoras, num jogo de contra rima e rima, aqui o que existe é uma verdadeira torre amplificando a boa-nova cristã ao final de cada respiração. É como se ouvíssemos a pancada forte num sino, seguida de sua réplica.

No sermão que pregou na Madre de Deus Dom João Franco de Oliveira pondera o Poeta a fragilidade humana.

Na oração, que desaterra - aterra,

Quer Deus, que, a quem está o cuidado - dado

Pregue, que a vida é emprestado - estado

Mistérios mil, que desenterra - enterra.

Quem não cuida de si, que é terra - erra

Que o alto Rei por afamado - amado,

É quem lhe assiste ao desvelado - lado

Da morte ao ar não desaferra - aferra.

Quem do mundo a mortal loucura - cura, A vontade de Deus sagrada - agrada, Firmar-lhe a vida em atadura - dura. 
Ó voz zelosa, que dobrada - brada

Já sei, que a flor da formosura - usura

Será no fim dessa jornada - nada.

(MATOS, 2013, p. 121)

Afirmando o rito da oração que nivela (desaterrar) a todos diante de Deus, o verso também ratifica o medo (aterrar) do pecador ao ser julgado. Ambos os termos estabelecem a ideia de que o corpo do cristão, em sua parcela material, foi criado da terra e a ela será devolvido na morte. A pregação revela (desenterra) e espiritualiza o mistério encerrado (enterra) do homem como matéria e espírito. A noção de que o espírito do homem vem do sopro divino e eterno, mas está enterrado num corpo perecível e concupiscente. $\mathrm{Ou}$ seja, a melhor parte, o espírito, reside provisoriamente na pior, a carne, a qual, ainda assim, pode lançar o homem na perdição. A oração contribui para livrar as coisas mundanas do corpo que, baixo e sem as rédeas da lei, conduziria a alma à perdição. A voz do pregador (dobrada) multiplica o evangelho - e o verbo dobrar é usado para os dobres do sino - proclama (brada) incisivo que aquilo que se investe no corpo pelo corpo (formosura), ou no mundo pelo mundo (usura), jamais salvará alguém. A doença do mundo é, nesse sentido, a valorização das coisas vãs, ou seja, que não conduzem à gloria em Deus, a única possível e meta de todo temente. Aplicar beleza adicional ao corpo, em busca de elogio, é vaidade; emprestar dinheiro ao semelhante, em troca de juros e não como caridade, é cobiça. Dentro do gênero demonstrativo, o poema vitupera os pecados que, no fundo, são os princípios do mercantilismo, à época não raro imputados a judeus e calvinistas. Que poema não faria hoje Gregório, quando o próprio Vaticano é o principal acionista de um banco dentro dos moldes capitalistas?

A harmonia dos eventos semântico-fonéticos parece sugerir a música polifônica - ou "canto de órgão", no dizer da época - em parte sugerida no arranjo vocal de Alê Siqueira (1972-) para a melodia de José Miguel Wisnik (1948-) sobre o soneto, rebatizado de "Mortal Loucura" e 
interpretado por Caetano Veloso (1942-). A criação de Wisnik ${ }^{2}$ assentase num equívoco sobremodo útil aqui. Há uma função litúrgica no texto de Gregório de Matos, o qual busca emular, em português, algo da Missa Rezada, isto é, falada em latim. Mas Wisnik (2005) transportou o soneto para a Missa Cantada que, em geral, utilizava o latim escrito, mas sem estilização erudita. Em lugar da polifonia esperada, ouve-se algo entre o cantochão silábico (cada sílaba métrica uma nota musical) e o fraseado característico do aboio e do baião. O tema melódico empregado - sequência das notas de $1^{\circ}, 2^{\circ}, 3^{\circ}, 4^{\circ}$ sustenido, $5^{\circ}, 4^{\circ}$ sustenido, $3^{\circ}, 1^{\circ}$, $1^{\circ}$ e $1^{\circ}$ graus na escala diatônica - revela na prática composicional certo anacronismo também perceptível na própria interpretação crítica de Wisnik, que antevê em Gregório de Matos o repentista típico do século XX. Esdrúxula e criativa, a canção de Wisnik evidencia que a versificação clássica e literária é às vezes rígida demais para a flexibilidade entoativa da canção popular moderna. Nesse simulacro de época, até um violão de 12 cordas, no arranjo, imita a viola de arame, muito usada pelos padres coloniais, às vezes em substituição ao cravo. Para uma sobreposição verossímil entre melodia falada, religiosidade popular, jogo anafórico e versificação oral, ouça-se a toada-reza Canção Nordestina (1964), de Geraldo Vandré (1935-).

José Miguel Wisnik ([1975] 1992, p. 16) projeta em Gregório de Matos o itinerante, o frequentador de festas populares, ou seja, o artista "com muito maior pertinência na sociedade, na qualidade de cantador transmissor de poesia e notícia, comunicador [...] do que como poeta culto, bacharel ou sacerdote”. Ao menos nesse mal-entendido, alinha-se a José Ramos Tinhorão (1998, p. 59-60), segundo o qual, assim como a obra de Domingos Caldas Barbosa (1739-1800), a de Gregório “deveria ser estudada quase toda como obra poética mas como versos de música popular urbana”. O estudioso que trabalha para restituir as preceptivas da poesia escrita à época, só pode tomar tais interpretações como enxertos, no colonial, de valores correntes a partir do século XIX. Trata-se de

2 Cf. VELOSO; WISNIK, 2005. 
uma leitura demasiado literária e pouco poético-retórica, que enxerga a versificação culta como mera limitação de medidas, rimas e acentos, e não como disposição linguística engenhosa, convencionada para a performance oratória artificial, normativa e social.

No século XVII, e não apenas nele, são produzidos poemas para recitação e canto. Segundo João Adolfo Hansen e Marcello Moreira (2013, p. 285), "a socialização da poesia" dá-se tanto na "leitura pública oralizada" quanto na "leitura privada silenciosa", esta podendo acontecer em voz alta ou sussurrada. "A leitura pública aproxima-se da récita que, contrariamente àquela, pode não depender da elocução do escrito e acabado, mas, sim, da capacidade de improvisação do poeta, que pode compor e recitar ao mesmo tempo" (HANSEN; MOREIRA, 2013, p. 285). Formas como décimas e sonetos podem ser utilizadas em ambos padrões: quando compostas na escrita para a performance, tendem a ser fixas e encerradas em si; quando realizadas na própria performance, tendem a operar como semifixas e, portanto, abertas a continuações, inclusive por parte de outros poetas.

\section{Só VOGA QUEM TEM DINHEIRO}

$[\ldots]$

Nesta vida transitória,

A base mais principal

É ter o seu capital,

E tudo mais é história.

Lá no tribunal da glória,

Regula Deus verdadeiro,

Porém cá no mundo inteiro,

Enquanto a mim, me parece,

Que quem não tem não merece,

Só voga quem tem dinheiro.

[...]

(CARVAlHo, 1967, p. 133)

Nesse exemplo de décima, recolhido por Rodrigues de Carvalho no XIX e publicado em 1903, lê-se um texto eficiente como performance 
pouco dependente de estratégias letradas, repleto, de fato, de traços orais reprováveis na versificação culta e oratória manejada por um Gregório de Matos. A redundância (mais principal), as cacofonias por repetições seriadas (mim, me; que quem) e, sobretudo, o uso de conectivos (porém, enquanto, que e só) movidos antes pelo fluxo discursivo que pela lógica coesiva, confirmam, aí sim, a fala mais ou menos espontânea e vulgar, pouco bacharelesca ou sacerdotal, empregada artificialmente por Gregório, no máximo, para satirizar negros, índios, mestiços, mulheres, pecadores ou néscios.

\section{Gregório de Matos in AN ANAPHORA RHYTHM}

\section{Abstract}

The anaphora works as a frame of words or expressions in the start of consecutive or alternating verses. In terms of rhetoric, it emphasizes the speaker's voice, since the intonation recurrence strengthens the words necessary to convince the listener. In poetic composition, the rhymes standardize the final sound of the verses, and the anaphora creates an acoustic uniformity at the beginning, generating a counter-rhyme effect. The refined application of this figure results in poetic grace, rhetorical conviction and theological didactics. Such matters will be discussed from two sonnets attributed to Gregório de Matos e Guerra (1633-1696).

KeYwords: Poetry of the seventeenth century; Gregório de Matos; poetic rhythm.

\section{Gregório de Matos en El RitMo de LAS ANÁforas}

\section{RESUMEN}

La anáfora es una disposición de palabras o expresiones al principio de versos que se sucenden o se alternan. Como figura retórica, ella señala la voz del orador, ya que la entonación recurrente subraya las palabras pertinentes para el convencimiento del auditorio. Si las rimas regularizan la sonoridad al final, la anáfora crea cierta uniformidad acústica al principio de los versos, en un interesante efecto de contra la rima. La aplicación aguda de tal figura - que 
alcanza gracia poética, convencimiento retórico y didáctica teológica - habrá de ser estudiada en dos sonetos sacros atribuídos a Gregório de Matos e Guerra (1633-1696).

Palabras Clave: Poesía del siglo XVII; Gregório de Matos; ritmo poético.

REFERÊNCIAS

ALBANO, José. Rimas [1912]. Poesia reunida e prefaciada por Manuel Bandeira. Rio de Janeiro: Graphia Editoral, 1993.

BOSI, Alfredo. Imagem, discurso. In: . O ser e o tempo da poesia. São Paulo: Cultrix, 1977.

CAGLIARI, Luiz Carlos. Línguas de ritmo silábico. Revista de Estudos da Linguagem, Belo Horizonte, v. 20, n. 2, 2012.

CARVALHO, José Rodrigues de. Poesias de diversas origens. In:

Cancioneiro do Norte. Rio de Janeiro: MEC/INL, 1967.

CHOCIAY, Rogério. O Boca e suas ferramentas: as formas poemáticas. In: . Os metros do Boca: teoria do verso em Gregório de Matos. São Paulo: Editora da UNESP, 1993.

FALCÃO, Edgard de Cerqueira. As imagens do Senhor Bom Jesus, veneradas em Matosinhos (Portugal) e em Congonhas do Campo (Brasil). In: COLÓQUIO DE ESTUDOS LUSO-BRASILEIROS, 4., 1959, Salvador. Anais... Bahia, Salvador.

FIORIN, José Luiz. Figuras de repetição de uma palavra ou sintagma em outra oração ou verso: anáfora, mesodiplose, epífora ou epístrofe. In:

Figuras de retórica. São Paulo: Editora Contexto, 2014.

HANSEN, João Adolfo. A civilização pela palavra. In: LOPES, Eliane Marta Teixeira; FARIA FILHO, Luciano Mendes; VEIGA, Cynthia Greive (Org.). 500 anos de educação no Brasil. Belo Horizonte: Autêntica, 2007.

HANSEN, João Adolfo; MOREIRA, Marcello. Índices de oralidade. In:

Para que todos entendais: poesia atribuída a Gregório de Matos e Guerra; letrados, manuscritura, retórica, autoria, obra e público na Bahia dos séculos XVII e XVIII. Belo Horizonte: Autêntica Editora, 2013. (v. 5). 
MARTINS, Paulo. Uma visão periegemática sobre a écfrase. Revista Clássica, Belo Horizonte, v. 29, n. 2, 2016.

MATOS, Gregório de. Poemas atribuídos: códice Asensio-Cunha. Organização João Adolfo Hansen e Marcello Moreira. Belo Horizonte: Autêntica Editora, 2013. (v. 1).

MATOS, Gregório de. Poemas. In: SILVA RAMOS, Péricles Eugênio da (Org.). Poesia Barroca: antologia. São Paulo: Melhoramentos, 1967.

MONTE ALVERNE, João de Deus. Sermão da prodigiosa, e admirável imagem do Santo Cristo de Matozinhos. In: PINTO, António Cerqueira. Historia da prodigiosa imagem de Cristo crucificado, que com o titulo de Bom Jesus de Bouças se venera no lugar de Matozinhos na Lusitânia. Lisboa: Oficina de Antonio Isidoro da Fonseca, 1737.

NASCIMENTO, Abdias. A estética da brancura nos artistas negros aculturados. In: - O genocídio do negro brasileiro: processo de um racismo mascarado [1978]. São Paulo: Editora Perspectiva, 2018.

QUINTILIANO, Marcos Fábio. Livro IX. In: . Instituição Oratória [circa 95]. Tradução, apresentação e notas Bruno Fregni Bassetto. Campinas, SP: Editora da Unicamp, 2016.

TINHORÃO, José Ramos. Gregório de Matos: glosa em cantigas no Recôncavo baiano. In: . História social da música popular brasileira. São Paulo: 34, 1998.

VANDRÉ, Geraldo. Canção Nordestina. In: . Geraldo Vandré. São Paulo: Audio Fidelty do Brasil, 1964.

VELOSO, Caetano; WISNIK, José Miguel. "Mortal Loucura”. In: Oncotô. São Paulo: Grupo Corpo, 2005.

VIEIRA, Antônio. Sexagésima [1655]. In: . Sermões. Organização, introdução e notas Alcir Pécora. São Paulo: Hedra, 2000. p. 46. (v. 1).

WISNIK, José Miguel. Introdução. In: MATOS, Gregório de. Poemas escolhidos: Gregório de Matos [1975]. São Paulo: Cultrix, 1992.

Submetido em 20 de maio de 2019

Aceito em 12 de setembro de 2019

Publicado em 15 de outubro de 2019 